\title{
Predictive model of the dependence of the cost of insulation on thermal characteristics
}

\author{
Olga Gamayunova ${ }^{1, *}$, Anton Radaev ${ }^{1}$, Mikhail Petrichenko ${ }^{1}$, Raimond Bogdanivics ${ }^{2}$ \\ ${ }^{1}$ Peter the Great St. Petersburg Polytechnic University, St. Petersburg, Russian Federation \\ ${ }^{2}$ Riga Technical University, Riga, Latvia
}

\begin{abstract}
In the market of building materials today there is a large selection of various thermal insulation materials, differing in cost, thermal conductivity and other characteristics. This article describes the predictive model of the cost of insulation from thermal characteristics, such as: thickness, thermal conductivity, (average) density, water absorption and combustibility group. The coefficient of determination was used to assess the quality of the obtained economic-mathematical model. The described predictive model can be effectively used to solve problems associated with determining the optimal characteristics of insulation by the criterion of minimizing cost.
\end{abstract}

\section{Introduction}

Energy efficiency of buildings and structures is the minimum energy consumption for the functioning of the full energy supply of buildings. A range of measures helps to achieve energy efficiency and energy saving, from replacing incandescent lamps with energy-saving ones, to high-quality thermal insulation of a house, leading to rational energy consumption for heating and cooling rooms.

Russian and foreign researchers are increasingly raising issues of energy efficiency and energy conservation, including issues of insulation of the outer walls of buildings and structures [1-10].

Quite stringent requirements are currently imposed on the heat-insulating material: it must possess not only high heat-shielding ability, but also be non-combustible, envi-ronmentally and hygienically safe, with high vapor permeability. Compliance with these requirements allows, in addition to effective insulation of the building, to signif-icantly improve sound insulation, to provide optimal microclimate parameters, which means comfortable living of a person. The study of thermal insulation materials is reflected in the works of such authors as: Miloradova N., Abramyan S.G., Mikhailo-va N.A., Kotlyarevsky A.A., Semochkin V.O. [11,12]

A great influence on the performance of enclosing structures has a humidity state of materials. An increase in the moisture content in the material of the fence above the normal (calculated) value leads to a decrease in the heat-shielding qualities of the building envelope. Along with the violation of the normal temperature and humidity conditions inside the building, an increase in the humidity content of the material of the enclosing structures can also have a big impact on the durability of the fence both in terms of the frost resistance of the material and its moisture resistance and biosta-bility.
Thermal regime and humidity conditions of enclosing structures described in the works of such authors as: Musorina T.A., Vatin N., Gorshkov A., Nemova D., Tarasova D., Zaborova D., Selezneva A., Ishkov A. [1318]

The problem of making a decision when choosing the best solution to increase the thermal protection of a building is difficult due to the variety of factors affecting this choice. Each solution has some advantages and some disadvantages and due to the variety of factors it is not immediately clear which of the options is better (preferable) than others and why. Mathematical methods and models can help find the best solu-tion. Kotov E.V., Nemova D.V., Tarasova D.S., Statsenko E.A., Ostrovaia A.F., Mu-sorina T.A., Kukolev M.I. used in their work mathematical models describing the enclosing structures from point of view of their thermal characteristics $[19,20]$.

\section{Materials and methods}

To form a predictive model of the dependence of the cost of insulation on the ther-mal characteristics, multidimensional linear regression will be used. Regression analy-sis is a method of modeling measured data and studying their properties. Data con-sists of pairs of values of dependent and independent variables. The regression model is a function of an independent variable and parameters with a random variable added. Model parameters are adjusted so that the model best approximates the data.

The general purpose of multiple regression is to analyze the relationship between several independent variables (also called regressors or predictors) and the dependent variable.

Often used the following regression equation:

\footnotetext{
* Corresponding author: gamayunova@inbox.ru
} 


$$
\hat{y}_{i}=a_{0}+\sum_{i=1}^{n} a_{i} x_{i}
$$

where

$\hat{y}_{i}$ - dependent characteristic;

$a_{0}$ - free member of the regression model;

$a_{i}$ - regression coefficients;

$x_{i}$ - factor i affecting the dependent characteristic.

Given the number of factors and the number of samples of insulation the model can be write in the form:

$$
\hat{y}_{i}=a+a_{1} x_{1}+a_{2} x_{2}+a_{3} x_{3}+a_{4} x_{4}+a_{5} x_{5}(2)
$$

A necessary condition for the existence of an extremum is the equality to zero of derivatives with respect to each parameter. In the general case, the question of the existence and number of solutions is allowed only for linear systems of equations, when it is possible to advance the conditions that would guarantee the existence of a unique solution. That is why the linearity of the system in terms of parameters is important.

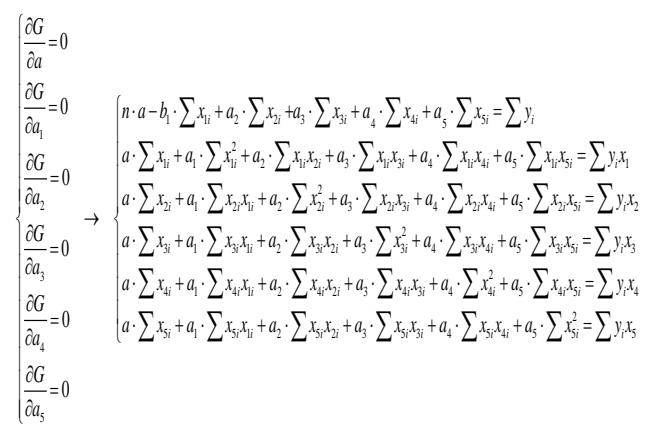

The main determinant of the system is:

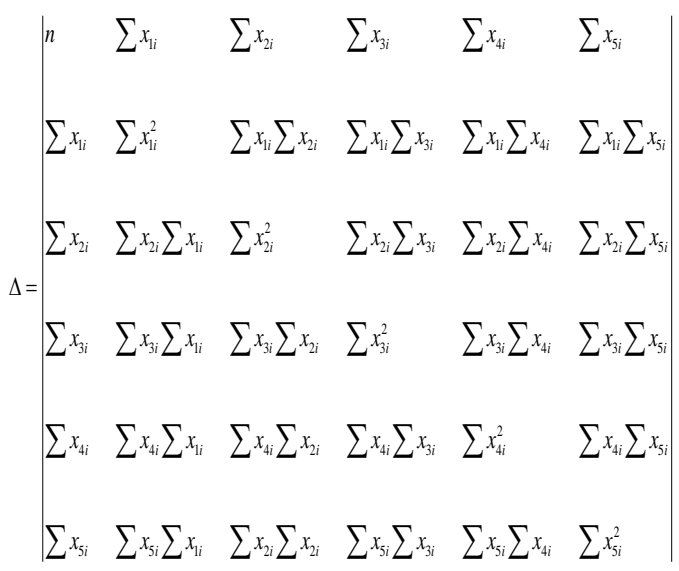

Free member column:

$$
\left\{\begin{array} { l } 
{ \sum y _ { i } } \\
{ \sum x _ { 1 i } y _ { i } } \\
{ \sum x _ { 2 i } y _ { i } - \text { System } } \\
{ \sum x _ { 3 i } y _ { i } \text { solution: } } \\
{ \sum x _ { 4 i } y _ { i } } \\
{ \sum x _ { 5 i } y _ { i } }
\end{array} \quad \left\{\begin{array}{l}
a=\frac{\Delta a}{\Delta} \\
a_{1}=\frac{\Delta a_{1}}{\Delta} \\
a_{2}=\frac{\Delta a_{2}}{\Delta} \\
a_{3}=\frac{\Delta a_{3}}{\Delta} \\
a_{4}=\frac{\Delta a_{4}}{\Delta} \\
a_{5}=\frac{\Delta a_{5}}{\Delta}
\end{array}\right.\right.
$$

$\Delta \mathrm{a}, \Delta \mathrm{a} 1, \Delta \mathrm{a} 2, \Delta \mathrm{a} 3, \Delta \mathrm{a} 4, \Delta \mathrm{a} 5$ - we get from the main determinant, replacing the first, second, etc. columns per column of free members.

Coefficient of determination R2:

$$
\begin{aligned}
& R^{2}=\frac{\sum\left(y_{i}-\hat{y}_{i}\right)^{2}}{\sum\left(y_{i}-\bar{y}\right)^{2}} \\
& \bar{y}=\frac{1}{n} \sum y_{i}
\end{aligned}
$$

where:

$\mathrm{yi}$ - actual values of the cost of insulation,

$\hat{y}_{i}$ - forecast (calculated) values of insulation cost,

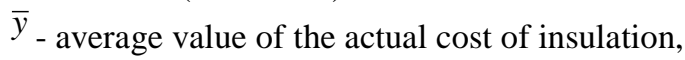

$\mathrm{n}$ - the number of samples of insulation.

The values of $\mathrm{R} 2 \in[0 ; 1]$, therefore, the closer $\mathrm{R} 2$ is to one, the sum of the squares of the forecast errors is less, and the influence of factors on the indicator under study is greater.

To ensure that the number of regressors (factors) does not affect the statistics of R2, it is usually replaced by an adjusted determination coefficient $R_{a d j}^{2}$ which gives a "penalty" for additionally included factors:

$$
R_{a d j}^{2}=1-\left(1-R^{2}\right) \cdot \frac{n-1}{n-k}
$$

where:

R2 - coefficient of determination,

$\mathrm{n}$ - number of observations (number of samples of insulation),

$\mathrm{k}$ - number of parameters, including free member.

\section{Results and Discussion}

The regression analysis tools described above were implemented using a practical example. All calculations were performed in Microsoft Excel. The calculations 
were carried out on the basis of heaters of the Knauf, Isoroc, Isover, Rockwool, Paroc, Ursa, Ecover, Penoplex, Technonikol, Master Term, Baswool brands in the amount of 130 samples presented on the building materials market in the North-West region of the Russian Federation.

In multivariate regression the dependence of the cost of insulation on the following factors was investigated:

$\delta \mathrm{i}$ - insulation thickness;

$\lambda \mathrm{i}$ - thermal conductivity coefficient;

$\rho i$ - (average) insulation density;

$\mu \mathrm{i}$ - water absorption (when fully immersed in water for 24 hours);

$\varphi \mathrm{i}-$ combustibility group.

Based on the initial data and the above formulas the main parameters of the regression model were determined (Table 1), as a result of which the model took the form:

$\hat{y}_{i}=-251.95+2962.73 \cdot x_{1}+112.514 \cdot x_{2}+2.43 \cdot x_{3}+4.79 \cdot x_{4}+92.28 \cdot x_{5}$

Table 1. Model parameters

\begin{tabular}{|c|c|c|c|c|}
\hline $\begin{array}{l}\mathrm{N} \\
\mathrm{o}\end{array}$ & Parameter name & Unit rev. & $\begin{array}{l}\text { Identified } \\
\text { / Formula }\end{array}$ & Value \\
\hline 1 & Cost constant & rub. $/ \mathrm{m}^{2}$ & $\begin{array}{c}a_{0}=\Delta a_{0} / \\
\Delta\end{array}$ & -251.951 \\
\hline 2 & $\begin{array}{l}\text { The coefficient of } \\
\text { proportionality of the } \\
\text { unit cost of insulation } \\
\text { value of the parameter } \\
\delta\end{array}$ & $\mathrm{rub} . / \mathrm{m}^{3}$ & $\begin{array}{c}a_{1}=\Delta a_{1} / \\
\Delta\end{array}$ & $\begin{array}{c}2,962.73 \\
2\end{array}$ \\
\hline 3 & $\begin{array}{l}\text { The coefficient of } \\
\text { proportionality of the } \\
\text { unit cost of insulation } \\
\text { value of the parameter } \\
\lambda\end{array}$ & $\frac{\mathrm{rub} \cdot{ }^{\circ} \mathrm{C}}{\mathrm{m} \cdot \mathrm{W}}$ & $\begin{array}{c}a_{2}=\Delta a_{2} / \\
\Delta\end{array}$ & 112.514 \\
\hline 4 & $\begin{array}{l}\text { The coefficient of } \\
\text { proportionality of the } \\
\text { unit cost of insulation } \\
\text { value of the parameter } \\
\rho\end{array}$ & $\frac{\mathrm{rub} \cdot \mathrm{n}}{\mathrm{kg}}$ & $\begin{array}{c}a_{3}=\Delta a_{3} / \\
\Delta\end{array}$ & 2.431 \\
\hline 5 & $\begin{array}{l}\text { The coefficient of } \\
\text { proportionality of the } \\
\text { unit cost of insulation } \\
\text { value of the parameter } \\
\mu\end{array}$ & $\frac{\text { rub. }}{\mathrm{m}^{2} \% \%}$ & $\begin{array}{c}a_{4}=\Delta a_{4} / \\
\Delta\end{array}$ & 4.793 \\
\hline 6 & $\begin{array}{l}\text { The coefficient of } \\
\text { proportionality of the } \\
\text { unit cost of insulation } \\
\text { value of the parameter } \\
\varphi\end{array}$ & $\mathrm{rub} . / \mathrm{m}^{2}$ & $\begin{array}{c}a_{5}=\Delta a_{5} / \\
\Delta\end{array}$ & 92.283 \\
\hline 7 & $\begin{array}{l}\text { Coefficient of } \\
\text { determination }\end{array}$ & - & $R^{2}$ & 0.893 \\
\hline 8 & $\begin{array}{l}\text { Number of } \\
\text { parameters, including } \\
\text { free member }\end{array}$ & units & $k$ & 6 \\
\hline 9 & $\begin{array}{l}\text { Adjusted coefficient } \\
\text { of determination }\end{array}$ & - & $R^{2}$ adj & 0.889 \\
\hline
\end{tabular}

It is important to note that for the predictive model described above, the determination coefficient is 0.893 (the adjusted determination coefficient is 0.889), which indicates the high adequacy of this model and, as a consequence, its high practical significance.

\section{Conclusion}

Requirements for energy efficiency ofenclosing structures are determined taking into account economic feasibility. The required values of the heat transfer resistance of the enclosing structures must be achieved without much increase in the cost of construction. In temperate climates, as well as in colder climates, singlelayer walls cannot ensure compliance of the building with thermal protection standards. To achieve the requirements of the standard for heat saving need to choose the right thermal insulation material.

The implementation of the predictive model described above for the dependence of the cost of insulation on thermal characteristics on a practical example confirmed its adequacy which allowed us to conclude that the developed model is of high practical importance. The predictive model described above can be effectively used to solve problems associated with determining the optimal characteristics of heaters according to the criterion of cost minimization. Appropriate calculations are planned for the next stages of the study.

\section{References}

1. D. N. Tseytin, N. I. Vatin, D. V. Nemova, P. P. Rymkevich, and A. S. Gorshkov, Constr. Unique Build. Struct. 1, 20 (2016)

2. V. G. Mokov and T. S. Demyanenko, J. Comput. Eng. Math. 6, 48 (2019)

3. A. Walsh, D. Cóstola, and L. C. Labaki, Build. Environ. 112, 337 (2017)

4. T. N. Vahnina, I. V. Susoeva, and A. A. Titunin, Mag. Civ. Eng. 83, 136 (2018)

5. E. G. Slobodchikov, V. N. Rozhin, and A. E. Mestnikov, Basic Res. 9, 357 (2017)

6. T. Meshcheryakova, in MATEC Web Conf., edited by A. Mottaeva and B. Melović (2018), p. 05005

7. J. C. L. Castro, D. D. Zaborova, T. A. Musorina, and I. E. Arkhipov, Mag. Civ. Eng. 8, 50 (2017)

8. T. Bezdenezhnukh, A. Kuritsyn, and I. Gimelshtein, in MATEC Web Conf., edited by P. Vitaliy Vladimirovich (2018), p. 02009

9. A. S. G. S.V. Korniyenko, N.I. Vatin, Constr. Unique Build. Struct. 12, 45 (2016)

10. A. Y. Zhigulina and A. M. Ponomarenko, in E3S Web Conf., edited by D. Safarik, Y. Tabunschikov, and V. Murgul (2018), p. 02003

11. O. Gamayunova, E. Gumerova, and N. Miloradova, E3S Web Conf. 33, 02046 (2018)

12. S. G. Abramyan, N. A. Mikhailova, A. A. Kotlyarevsky, and V. O. Semochkin, Inzhenernyy Vestn. Dona 4, 221 (2018)

13. T. A. Musorina, O. S. Gamayunova, and M. R. Petrichenko, Proc. Moscow State Univ. Civ. Eng. MGSU 13, (2018)

14. O. Gamayunova, T. Musorina, and A. Ishkov, in E3S Web Conf. (2018)

15. N. Vatin, A. Gorshkov, D. Nemova, O. Gamayunova, and D. Tarasova, Humidity Conditions of Homogeneous Wall from Gas-Concrete Blocks with Finishing Plaster Compounds (2014)

16. D. Zaborova, T. Musorina, A. Selezneva, and A. Butyrin, Adv. Intell. Syst. Comput. 692, 473 (2017)

17. D. Zaborova, G. Vieira, T. Musorina, and A. Butyrin, Adv. Intell. Syst. Comput. 692, 482 (2017)

18. V. V. Sergeev, M. R. Petrichenko, D. Nemova, E. V. 
Kotov, D. S. Tarasova, A. V. Nefedova, and A. Borodinecs, Mag. Civ. Eng. 8, 67 (2018)

19. E. A. Statsenko, A. F. Ostrovaia, T. A. Musorina, M. I. Kukolev, and M. R. Petritchenko, Mag. Civ. Eng. 68, 86 (2016)

20. M. R. Petritchenko, E. V. Kotov, D. V. Nemova, D. S. Tarasova, and V. V. Sergeev, Mag. Civ. Eng. 77, 130 (2018) 